\title{
Imhof und die Stadt
}

Erhard Taverna

1 Mitscherlich A.

Die Unwirtlichkeit unserer Städte - Anstiftung zum Unfrieden. Frankfurt: Edition Suhrkamp; 1969.

2 Foucault M. Dits et écrits. Schriften. Frankfurt: Suhrkamp Verlag; 2001.

erhard.taverna@saez.ch
Es sind schon über vierzig Jahre her, dass Alexander Mitscherlich, Direktor der Psychosomatischen Universitätsklinik in Heidelberg, die «Unwirtlichkeit unserer Städte» [1] beklagte. Er meinte damit nicht nur seine Heimat, wo Neubauten möglichst rasch die Trümmerhaufen zu ersetzen hatten. «Die hochgradig integrierte alte Stadt hat sich funktionell entmischt», lautete die Diagnose des auf Neurosen spezialisierten Klinikers. Er schrieb gegen «den Trübsinn der Zeit in einer Sache, die sich ändern liesse». Nur die gestaltete Stadt könne Heimat werden, denn Heimat verlange «Markierungen der Identität eines Ortes». Mit dieser Identität scheint etwas nicht zu stimmen, wenn heute Landwirtschaftsschulen überlaufen und Städter Sennen werden wollen. Gipfel und Alpenglühen sind ein Dauerthema, die Stadt oder was von ihr übrig blieb, hat eine schlechte Presse. Die Möchte-Gern-Bergler sind wieder einmal auf der Suche nach dem sinnstiftenden Raum, Sennentuntschi hin oder her.

Imhof war ein stadtbekannter Penner. Stets barhäuptig, auch wenn es regnete, trug er einen ausgebeulten Frack mit zahlreichen Flicken und einem ausgefransten Schwalbenschwanz, der ihm wie ein Lendenschurz über dem Hintern hing. Seine speckige Ledermappe begleitete ihn überall. Sie war prall mit Notenblättern gefüllt, denn Imhof war ein Musiker, ein gescheiterter Klaviervirtuose, und die Innenstadt sein Revier. Vier öffentliche Plätze mit stattlichen Brunnen markierten die Eckpunkte seiner täglichen Rundgänge. Von der ersten Fliederblüte bis zum herbstlichen Einfall krächzender Dohlen bewegte er sich täglich im Viereck seiner Badestuben, wo er ungestört und ausgiebig seine Füsse wusch. Er sprach mit Menschen, die ausser ihm keiner sah oder hörte. An seiner anstrengenden Arbeit litt er nicht, denn nie hätte er ein Angebot mit warmem Wasser, Seife und Handtuch angenommen. Es mussten diese vier Brunnen sein, wuchtig gemauerte Becken mit aufragenden Säulen, geschichtsträchtigen Wappen und Reliefs mehr oder weniger ruhmreicher Ereignisse der Kleinstadt am Rhein, aus deren Röhren sich kräftige Strahlen eiskalt ergossen. Handwerker und Ladenbesitzer konnten die Arbeitszeit nach ihm richten, denn pünktlich wie die benachbarten Kirchenuhren begann sein Waschritual. Hosenbeine hochkrempeln, löchrige Socken ausziehen und durchgetretene Schuhe sorgfältig nebeneinander stellen. Wer ihn kannte, ignorierte ihn bei seiner Arbeit, nur Kinder und Passanten, die sich über die seltsame Figur wunderten, blieben in respektvollem Abstand stehen. Imhof verstand sich

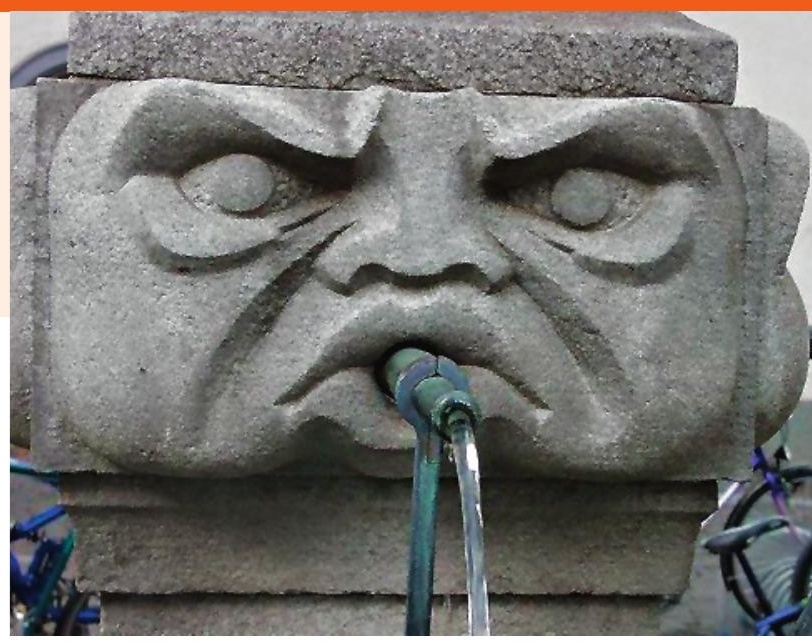

auf Märchen und erschreckte gerne seine Zuhörer mit wunderlichen Vorfällen, denen stets eine reale Begebenheit zugrunde lag, die er mit morbider Lust phantastisch verzerrte. Viele mieden ihn aus diesem Grund, anderen las er aus der Hand, und wieder andere verpflegten ihn mit seiner Lieblingsspeise - Milchreis mit reichlich Zucker und Zimt. Im Winter spielte er Piano an Weihnachtsabenden, umständlich die Frackschösse ordnend und stets mit peinlich ausgerichteten Schuhen neben dem Drehstuhl. Oft unterbrach er seine Vorführungen und veränderte deren Lage um einige Millimeter. Mehrere Kirchen beschäftigten ihn als Ersatzorganist. Böse Mäuler behaupteten, dass seine Auftritte mehr Kirchgänger anlockten als die Predigten.

So wie Imhof gab es noch andere «Originale», die öffentliche Strassen und Plätze in Beschlag nahmen, um dort die eigenen Gegenräume einzurichten. Der französische Soziologe Michel Foucault hat diese Zonen in einem Essay «Des espaces autres» [2] als Heterotopien beschrieben. Orte, die gleichzeitig für unterschiedlichste Zwecke gebraucht werden, konkurrierende Bereiche, die nicht eindeutig definiert sind, auch Kindern und Narren zugänglich. Oder moderne, institutionelle Orte, die Foucault besonders interessiert haben, wo eine durchstrukturierte Gesellschaft ihre von der Norm abweichenden Bürger aussperrt und behandelt. Denn mit den Abrissbirnen, den Baukränen und den Automobilen kam auch der medizinische Fürsorgeapparat. Imhof verschwand nach mehreren Insulinkuren, und die übrigen Abweichler lernten diverse Anstaltsordnungen kennen. Ihre heutigen Nachfolger, die Obdachlosen und die unterschiedlichsten Randexistenzen, sind in die Nischen der Subszenen abgetaucht. In die Ödnis der Durchgangszonen, der verwahrlosten Parks, der Bahnhöfe, Autoschneisen und abgehängten Quartiere. Den Rest schlucken die Gegenwelten der Sozialprogramme, Fürsorgestellen und Therapiestationen. Die alte Show fände keine Bühne in der fragmentierten Stadt und auch keine Zuschauer. Denn die gestressten Passanten sind auf der Suche nach einem Parkplatz. Sie haben es eilig. Es locken der Einkauf oder eine Abendmordserie. 